\title{
Stationary Wavelet Transform based Image Fusion using fusion rules
}

\author{
Nainavarapu Radha, Tummala Ranga Babu
}

\begin{abstract}
Multifocus image fusion is a current research topic in the area of image processing for visual sensor networks. Discrete wavelet transform based fusion algorithms suffer from unintended effects like smoothing of edges, loss of contrast and artifacts. To overcome these problems, Stationary Wavelet Transform based algorithm using fusion-rules is proposed and applied to multifocus images. Stationary Wavelet Transform well preserves the edges and avoid artifacts with its shift-invariance property. Entropy and spatial frequency based fusion rules in this work can effectively characterize the intensity variations in an image there by loss of contrast is minimized. Simulation results show that the proposed method can amply preserve the edges and also avoid artifacts with no loss of contrast.
\end{abstract}

Keywords: Stationary Wavelet Transform, Entropy, Image Fusion, Spatial Frequency, Fusion rules.

\section{INTRODUCTION}

In n visual sensor networks (VSN), the sensors are cameras which can capture, process and transmit a large number of images in surveillance, traffic and industrial applications [1]. However, an entire focused image is not captured by the cameras in visual sensor networks (VSN). This makes it difficult for VSN to analyze and understand the images. To address these issues, fusion techniques are desirable for fusing two or more images with divergent focus levels into a focused fused image.

\section{LITERATURE REVIEW}

The fusion techniques using Laplacian pyramids [2], Discrete Wavelet Transform (DWT) [3], discrete cosine transform [4], Walsh Hadamard Transform [5], multiresolution singular value decomposition (MSVD) [6], Wavelet based methods [7-12] are existing in the literature. The discrete wavelet transform (DWT) based method had been verified to be an effective image fusion technique. However, shift-variance property of DWT introduces unintended effects. The shift-invariant stationary wavelet transform (SWT) eliminates the unintended effects of DWT. Fusion rules are also essential to get a sharper fused image from source images considered for fusion. Hence, in this

Revised Manuscript Received on December 30, 2019.

* Correspondence Author

Nainavarapu Radha*, Department of ECE, Aditya Engineering College, Surampalem, India. Email: radha_naina@yahoo.com

Tummala Ranga Babu, Department of ECE, RVR \& JC College of Engineering, Guntur, India.

(C) The Authors. Published by Blue Eyes Intelligence Engineering and Sciences Publication (BEIESP). This is an open access article under the CC BY-NC-ND license (http://creativecommons.org/licenses/by-nc-nd/4.0/) paper stationary wavelet transform and fusion rules based algorithm proposed for fusion.

\section{PROPOSED METHODOLOGY}

(a) Multi-focused source images are considered for fusion.

(b) Perform RGB to YCbCr color Transform on source images.

(c) Apply 1-level SWT on source images to get low and high-frequency sub- bands using Eq. (1).

$$
\begin{aligned}
& c A_{j+1, k_{1}, k_{2}}=\sum_{n 1} \sum_{n 2} F_{0}^{\uparrow 2^{j}}\left(n_{1}-2 k_{1}\right) F_{0}^{\uparrow 2^{j}}\left(n_{2}-2 k_{2}\right) c A_{j, n_{1}, n_{2}} \\
& c D_{j+1, k_{1} k_{2}}^{h}=\sum_{n 1} \sum_{n 2} F_{0}^{\uparrow 2^{j}}\left(n_{1}-2 k_{1}\right) G_{0}^{\uparrow{ }^{j}}\left(n_{2}-2 k_{2}\right) c A_{j, n_{1}, n_{2}} \\
& c D_{j+1 k_{1} k_{2}}^{v}=\sum_{n 1} \sum_{n 2} G_{0}^{\uparrow 2^{j}}\left(n_{1}-2 k_{1}\right) F_{0}^{\uparrow 2^{j}}\left(n_{2}-2 k_{2}\right) c A_{j, n_{1}, n_{2}} \\
& c D_{j+1 k_{1} k_{2}}^{d}=\sum_{n 1} \sum_{n 2} G_{0}^{\uparrow 2^{j}}\left(n_{1}-2 k_{1}\right) G_{0}^{\uparrow 2^{j}}\left(n_{2}-2 k_{2}\right) c A_{j, n_{1}, n_{2}}
\end{aligned}
$$

(d) Spatial frequency based fusion rule is used to fuse low frequency coefficients in low- frequency sub- bands using Eqs. (2)-(4).

$$
\begin{gathered}
R F=\sqrt{\frac{1}{N \times N} \sum_{i=1}^{N} \sum_{j=2}^{N}[I(i, j)-I(i, j-1)]^{2}} \\
C F=\sqrt{\frac{1}{N \times N} \sum_{j=1}^{N} \sum_{i=2}^{N}[I(i, j)-I(i-1, j)]^{2}} \\
S F=\sqrt{(R F)^{2}+(C F)^{2}}
\end{gathered}
$$

(e) Entropy based fusion rule is used to fuse high frequency coefficients in high - frequency sub- bands using Eq. (5).

$$
E=\sum_{j=0}^{G} p(i) \log _{2} p(i)
$$

(f) Get composite fused image by applying l-level inverse SWT on low- and high-frequency sub-bands using Eq. (6).

$$
\begin{aligned}
& c A_{j, n_{1}, n_{2}}=\frac{1}{4} \sum_{i=0}^{3}\left\{\sum_{k_{1}} \sum_{k_{2}} F_{1}\left(n_{1}-2 k_{1}-i\right) F_{1}\left(n_{2}-2 k_{2}-i\right) c A_{j+1, k_{1}, k_{2}}\right. \\
& +\sum_{k_{1}} \sum_{k_{2}} F_{1}\left(n_{1}-2 k_{1}-i\right) G_{1}\left(n_{2}-2 k_{2}-i\right) c D_{j+1, k_{1}, k_{2}}^{h} \\
& +\sum_{k_{1}}^{k_{2}} \sum_{k_{2}} G_{1}\left(n_{1}-2 k_{1}-i\right) F_{1}\left(n_{2}-2 k_{2}-i\right) c D_{j+1, k_{1}, k_{2}}^{v} \\
& +\sum_{k_{1}} \sum_{k_{2}} G_{1}\left(n_{1}-2 k_{1}-i\right) G_{1}\left(n_{2}-2 k_{2}-i\right) c D_{j+1, k_{1}, k_{2}}^{d}
\end{aligned}
$$


(g) Transform fused image in YCbCr to RGB color space.

(h) Evaluate fused image quality using reference and nonreference performance measures.

\section{RESULTS AND DISCUSSION}

The proposed method is tested on artificial, natural and misregistered multi-focus images. The proposed method performance is compared with existing DWT [3], MSVD [6], SWT [8], DWT + Variance [9], and DTCWT [10] fusion methods in terms of performance measures.

The first experiment is performed on artificially created images. In this experiment two images Lena and Airplane [13] are used as reference. Artificial images were formed by convolution of referenced image with a Gaussian filter. Both reference and artificial images are shown in Fig. 1.



(a)

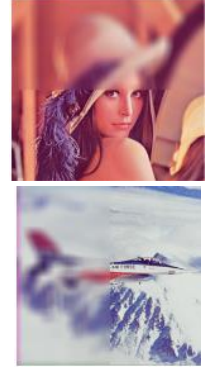

(b)

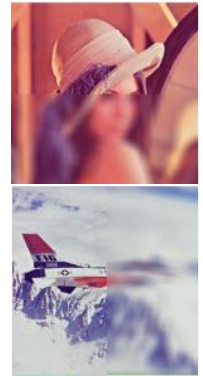

(c)
Fig. 1 (a) Reference images and (b)-(c) artificial images

The fused images are reflected in Fig. 2 and 3. The fused image quality is calculated, using reference measures PSNR and FSIM. In Table I, PSNR and FSIM values of all test images are high for fused image of proposed method.

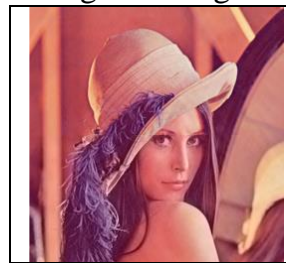

(a)

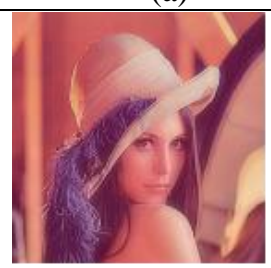

(d)

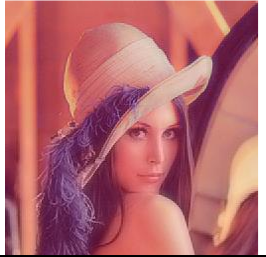

(b)

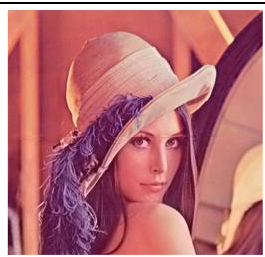

(e)



(c)

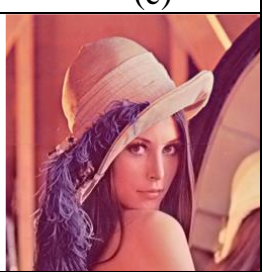

(f)
Fig. 2 Fused images (Lena) (a) DWT [3], (b) MSVD [6], (c) SWT [8], (d) DWT + Variance [9], (e) DTCWT [10] and (f) proposed method.



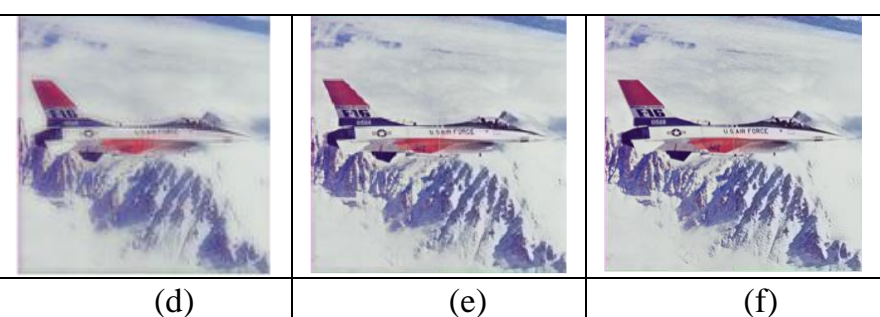

Fig. 3 Fused images (Airplane) (a) DWT [3], (b) MSVD [6], (c) SWT [8], (d) DWT + Variance [9], (e) DTCWT [10] and (f) proposed method.

Table- I: Comparison of PSNR and FSIM of different fusion methods

\begin{tabular}{|c|c|c|c|}
\hline $\begin{array}{l}\text { Artificial } \\
\text { Multi-Focus } \\
\text { Images }\end{array}$ & Fusion Method & PSNR & FSIM \\
\hline \multirow[b]{6}{*}{ Lena } & DWT [3] & 27.1013 & 0.9105 \\
\hline & MSVD [6] & 27.7903 & 0.9335 \\
\hline & SWT [8] & 28.2727 & 0.9374 \\
\hline & $\begin{array}{l}\text { DWT + Variance } \\
\text { [9] }\end{array}$ & 27.9178 & 0.9362 \\
\hline & DTCWT [10] & 32.9903 & 0.988 \\
\hline & Proposed method & 33.2801 & 0.9917 \\
\hline \multirow[b]{6}{*}{ Airplane } & DWT [3] & 25.3572 & 0.8859 \\
\hline & MSVD [6] & 26.3356 & 0.9173 \\
\hline & SWT [8] & 27.2888 & 0.9253 \\
\hline & $\begin{array}{l}\text { DWT + Variance } \\
{[9]}\end{array}$ & 26.3935 & 0.9182 \\
\hline & DTCWT [10] & 32.5604 & 0.9875 \\
\hline & Proposed method & 32.8355 & 0.9902 \\
\hline
\end{tabular}

The second experiment is run on natural multi-focus Map and Children images [14] with different focus levels are shown in Fig. 4 and 5.

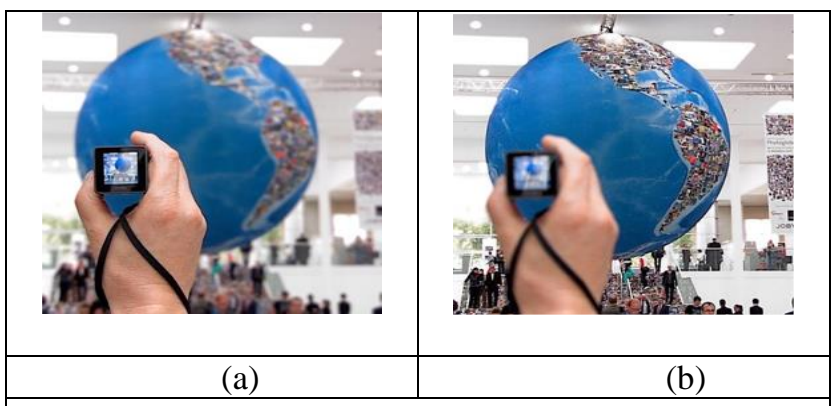

Fig. 4 Non-referenced Map image (a) foreground focused image (b) background focused image

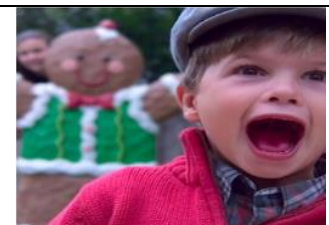

(a)

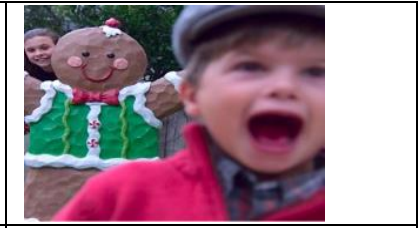

(b)
Fig. 5 Non-referenced Children image (a) reground focused image (b) background focused image 
The experimental results of Map and Children image are shown in Fig. 6 and 7. One could notice that the fused images of proposed method give good quality than other methods. Natural and misregistered image fusion performance is calculated using non-reference measures $\mathrm{Q}_{\mathrm{BC}}[15]$ and $\mathrm{QY}_{\mathrm{Y}}$ [16].

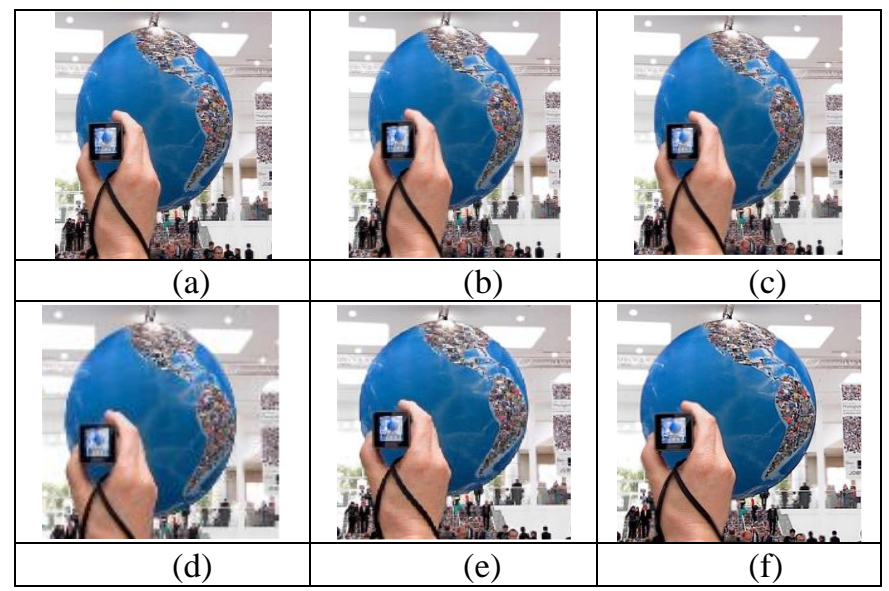

Fig. 6 Fused images (Map) (a) DWT [3], (b) MSVD [6], (c) SWT [8], (d) DWT + Variance [9], (e) DTCWT [10] and (f) proposed method.

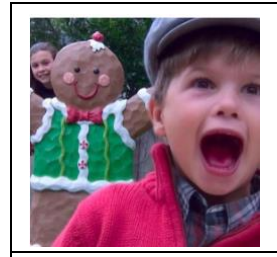

(a)

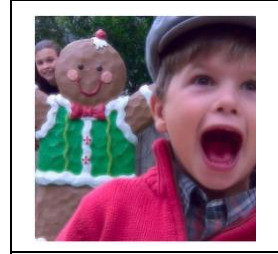

(d)

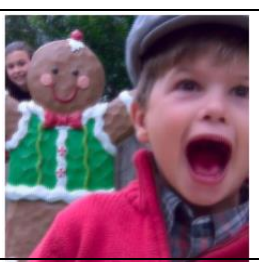

(b)

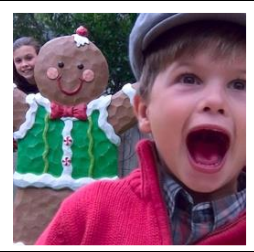

(e)

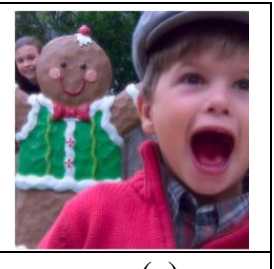

(c)

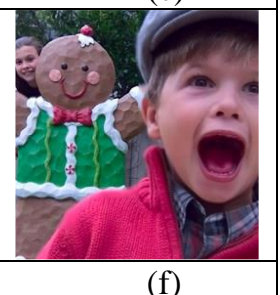

(f)

Fig. 7 Fused images (Children) (a) DWT [3], (b) MSVD [6], (c) SWT [8], (d) DWT + Variance [9], (e) DTCWT [10] and (f) proposed method.

Table II gives the comparison of various fusion methods. A high $Q_{B C}$ and $Q_{Y}$ value of proposed method shows that high contrast and sharpness are preserved in fused image.

Table- II: Comparison of QBC and QY of different fusion methods

\begin{tabular}{|l|l|l|r|}
\hline $\begin{array}{l}\text { Natural } \\
\text { Multi-Focus } \\
\text { Images }\end{array}$ & $\begin{array}{l}\text { Fusion } \\
\text { Method }\end{array}$ & $\mathrm{Q}_{\mathrm{CB}}$ & $\mathrm{Q}_{\mathrm{Y}}$ \\
\hline \multirow{5}{*}{} & DWT [3] & 0.7656 & 0.8645 \\
\cline { 2 - 5 } & MSVD [6] & 0.7711 & 0.9203 \\
\cline { 2 - 5 } & SWT [8] & 0.7733 & 0.9344 \\
\cline { 2 - 5 } & $\begin{array}{l}\text { DWT + } \\
\text { Variance [9] }\end{array}$ & 0.7589 & 0.9187 \\
\cline { 2 - 4 } Map & $\begin{array}{l}\text { DTCWT } \\
\text { [10] }\end{array}$ & 0.7778 & \\
\hline
\end{tabular}

\begin{tabular}{|l|l|r|r|} 
& $\begin{array}{l}\text { Proposed } \\
\text { method }\end{array}$ & $\mathbf{0 . 8 0 7 9}$ & $\mathbf{0 . 9 3 7 3}$ \\
\hline & DWT [3] & 0.709 & 0.8736 \\
\cline { 2 - 4 } & MSVD [6] & 0.7056 & 0.8304 \\
\cline { 2 - 4 } & SWT [8] & 0.7137 & 0.923 \\
\cline { 2 - 4 } & $\begin{array}{l}\text { DWT + } \\
\text { Variance [9] }\end{array}$ & 0.7028 & 0.9021 \\
\cline { 2 - 4 } Children & $\begin{array}{l}\text { DTCWT } \\
\text { [10] }\end{array}$ & 0.7248 & 0.9345 \\
\cline { 2 - 4 } & $\begin{array}{l}\text { Proposed } \\
\text { method }\end{array}$ & $\mathbf{0 . 7 5 1 3}$ & $\mathbf{0 . 9 4 9 5}$ \\
\hline
\end{tabular}

The third experiment is performed on misregistered multi-focus color images to assess the robustness of the proposed method.

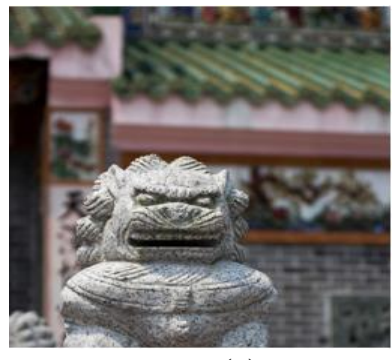

(a)

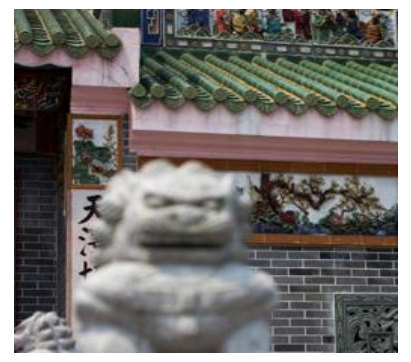

(b)
Fig. 8 The Temple Misregistered source images (a) Foreground Focused image (b) Background Focused image

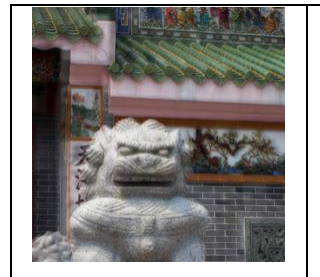

(a)

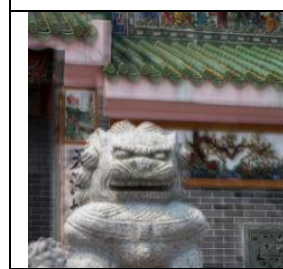

(d)

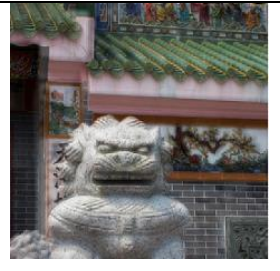

(b)

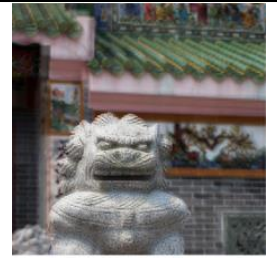

(c)
Fig. 9 Fused images (Temple) (a) DWT [3], (b) MSVD [6], (c) SWT [8], (d) DWT + Variance [9], (e) DTCWT [10] and (f) proposed method.

One pair of color images of the temple is considered for fusion. The source and fused images are shown in Fig. 8 and 9. We also compared the fusion results of temple in Table III. Fig. 10 describes that larger Qсв and Qy of proposed method specify better fused image quality.

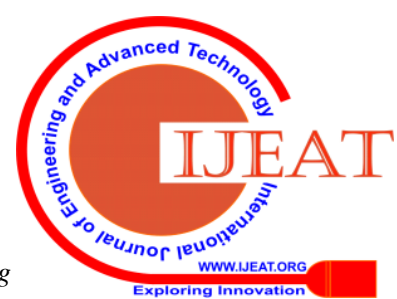


Table- III: Comparison of QBC and QY of different fusion methods

\begin{tabular}{|c|c|c|c|}
\hline $\begin{array}{l}\text { Misregistered } \\
\text { Multi-Focus } \\
\text { Images } \\
\end{array}$ & $\begin{array}{l}\text { Fusion } \\
\text { Method }\end{array}$ & $\mathrm{Q}_{\mathrm{CB}}$ & $\mathrm{Q}_{\mathrm{Y}}$ \\
\hline \multirow[b]{6}{*}{ Temple } & DWT [3] & 0.5482 & 0.7215 \\
\hline & MSVD [6] & 0.5618 & 0.8439 \\
\hline & SWT [8] & 0.5634 & 0.8701 \\
\hline & $\begin{array}{l}\text { DWT + } \\
\text { Variance [9] }\end{array}$ & 0.5526 & 0.8174 \\
\hline & DTCWT [10] & 0.6298 & 0.9102 \\
\hline & $\begin{array}{l}\text { Proposed } \\
\text { method }\end{array}$ & 0.7288 & 0.954 \\
\hline
\end{tabular}

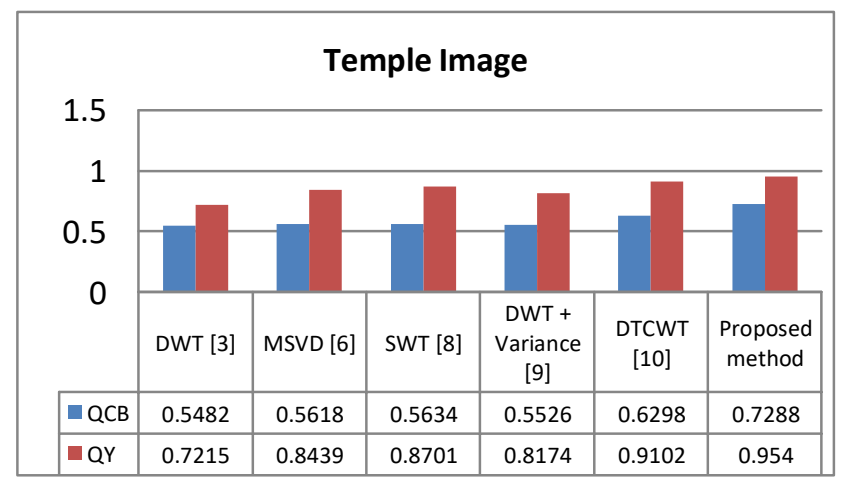

Fig. 10 Comparison for QсB and Qy

\section{CONCLUSION}

This paper proposes a stationary wavelet transform based image fusion using fusion rules for visual sensor networks. Due to its shift-invariance, SWT avoids unintended effects introduced by DWT. Fusion rules are effectively selected focused regions without loss of contrast. Experimental results prove that the proposed method produces a good quality fused image compared to other methods.

\section{REFERENCES}

1. B. Yue, S. Wang, X. Liang, L. Jiao, and C. Xu, “Joint prior learning for visual sensor network noisy image super-resolution," Sensors, vol. 16, no. 3, p. 288, 2016.

2. R. Sabre, and I. S Wahyuni, "Wavelet Decomposition in Laplacian Pyramid for Image Fusion", Int. J. of Sig. Proc. Syst, Vol.4, No.1, pp.37-44, 2016.

3. Wang WW, Shui PL, Song GX. Multifocus image fusion in wavelet domain. In: IEEE 2003 Machine Learning and Cybernetics International Conference; Xi'an, China; 2003. pp. 2887-2890.

4. L. Cao and L. Jin, "Multi-focus image fusion on spatial frequency in Discrete Cosine Transform domain”, IEEE Sig. Proce. Lett. 22(2), pp. 220-224, 2015.

5. N. Radha and T. Ranga Babu, Multifocus Color Image Fusion Based on Walsh Hadamard Transform and Sum- Modified-Laplacian Focus Measure, Int. J. of IES vol. 12(1), pp.142-150, 2019.

6. V.P.S. Naidu, "Image Fusion Technique using Multi-resolution Singular Value Decomposition", Def. Sci. J, Vol. 61, pp. 479-484, 2011.

7. W. W Wang, P. L Shui, and G. X Song, "Multifocus Image Fusion in Wavelet Domain", Int. Conf. on Mach Lear. Cyber, pp. 2887-2890, 2003.

8. S. T. Li, B. Yang, and J. Hu, "Performance comparison of different multi-resolution transforms for image fusion", Inf. Fus., Vol.12, pp.74-84, 2011.

9. Sahoo T, Mohanty S, Sahu S. Multi-focus image fusion using variance based spatial domain and wavelet transform. In: IEEE 2011
International Conference on Multimedia, Signal Processing and Communication Technologies, 2011. pp. 48-51.

10. N. Radha and T. Ranga Babu, Performance evaluation of quarter shift dual tree complex wavelet transform based multifocus image fusion using fusion rules, Int. J. Electric. Compute. Eng. Vol. 9(4), pp.2377-2385, 2019.

11. R. Singh and A. Khare, "Fusion of multimodal medical images using Daubechies complex wavelet transform-A multiresolution approach", Inf. Fus, Vol.19, pp.49-60, 2014.

12. A. Sharma and T. Gulati, "Change Detection from Remotely Sensed Images Based on Stationary Wavelet Transform," Inter. Jour. of ECE, vol. 7, pp. 3395-3401, 2017.

13. http://sipi.usc.edu/database.

14. http://mansournejati.ece.iut.ac.ir/content/lytro-multi-focus-dataset.

15. Y. Chen and R. S. Blum, A new automated quality assessment algorithm for image fusion, Imag. Vis. Comp, pp.1421-1432, 2009.

16. C. Yang and J. Q. Zhang, A novel similarity based quality metric for image fusion, Inf. Fusion. pp. 156-160, 2008.

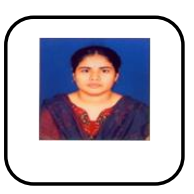

\section{AUTHORS PROFILE}

N Radha did AMIE from Institution of Engineers (India), Kolkata and Master of Technology from Jawaharlal Nehru Technological University, Kakinada. She is currently pursuing Ph.D. in Department of Electronics and Communication Engineering, Nagarjuna University, Guntur, Andhra Pradesh. Her main research work focuses on Digital image processing. She is presently working as an Associate professor in the department of Electronics and Communication Engineering in Aditya Engineering College, Surampalem.

Dr. Tummala Ranga Babu obtained his Ph.D. in Electronics and

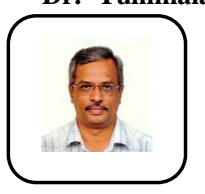
Communication Engineering from JNTUH, Hyderabad, M. Tech in Electronics \& Communication Engineering (Digital Electronics \& Communication Systems) from JNTU College of Engineering (Autonomous), Anantapur, M.S. (Electronics \& Control Engineering) from BITS, Pilani and B.E. (Electronics and Communication Engineering) from AMA College of Engineering (Affiliated to University of Madras). He is currently working as Professor and Head of Department of Electronics \& Communication Engineering in RVR \& JC College of Engineering (Autonomous). His research interests include Image Processing, Embedded Systems, Pattern Recognition, and Digital Communication. 